\title{
A CASE STUDY ON CONSTRAINTS AFFECTING THE PRODUCTIVITY OF READYMADE GARMENT (RMG) INDUSTRY IN BANGLADESH
}

\author{
C. L. Karmaker ${ }^{\mathrm{a}}$, M. Saha ${ }^{\mathrm{b}}$ \\ ${ }^{a}$ Department of Industrial and Production Engineering, Bangladesh University of \\ Engineering and Technology, Dhaka, Bangladesh. \\ ${ }^{\mathrm{b}}$ Department of Civil Engineering, Bangladesh University of Engineering and \\ Technology, Dhaka, Bangladesh.
}

\begin{abstract}
The success of Readymade garment (RMG) exports from Bangladesh over the past few decades has reached to an unprecedented height and sometimes it goes beyond optimistic expectations compared to any other sectors in the country. Being one of the lucrative multibillion dollar industries, it has provided more than 4.0 million employment opportunities and ensured women empowerment. It has brought the fortune to rural women communities and they have become independent by themselves. The garment industry in Bangladesh faces a number of challenges including fallacious working condition, dearth of safety, political turbulence and, low remuneration. To sustain in the competitive global market, management has to identify the prime key opportunities and identify any threats. This study was conducted to analyze the prospects and constraints of Bangladesh RMG industry using well known multi-criteria decision making (MCDM) method namely analytic hierarchy process (AHP). To judge the model, data was collected through the focus group discussion and key informant interviews with the managers of three different garment industries situated in Gazipur, Bangladesh. The findings of the study showed that "unsound working condition" among several challenges affects workers working capability and productivity severely. The study recommends that through proper identification and taking corrective measures against the challenges by the management of $R M G$ sector, Bangladesh has the opportunity to be the market leader in this sector.
\end{abstract}

\section{KEYWORDS:}

Readymade garment; Productivity; Competitiveness; Constraints; Multi criteria decision making; Analytic hierarchy process.

\section{INTRODUCTION}

Bangladesh is a South Asian country \& its economy is largely dependent on agriculture. Different Industries like textile industry, pharmaceuticals, agroindustry, jute, leather, tea and, food processing, have great influence on the national economic development of Bangladesh. The Ready-made Garment (RMG) sector is the highest earning foreign currency segment amongst all of them. Although Bangladesh does not produce cotton, it has become the second largest exporter of garment products after China in the world for last three decades (Farhana et al., 2015). It was the preferred destination for many countries even at the time of global economic recession. Low wage \& huge population of 161 million have brought fortunes on RMG industry.

DOI: $10.5121 /$ ijmvsc.2016.7305 
Starting its journey from 1980s, this sector has been fulfilling the international demand rather than emerging to meet local demands. In 1982-83, it had only $1.1 \%$ stake in the total export but in financial year (FY) 2013-14 the amount has increased to 79.63\%. According to Bangladesh Garment Manufacturers and Exporters Association (BGMEA) Members' Directory, Bangladesh earned US\$ 31.57 million in 1983 but this value stands at \$24.49 billion in FY 2013-14. According to the report on readymade garments industry of Bangladesh by Kiron (2015), in 1983-84, there were only 134 factories employing only 0.04 million people but in 2013-14 more than 4000 garment factories are running in this country creating employment opportunity about 4.0 million workers where more than 3.20 million (80\%) are women. It is a blessing for rural economically poverty stricken women folk as it has opened a new door to engage themselves into the economic activities of Bangladesh. It has helped to ensure the women empowerment of Bangladesh. Constraints exist related to garment export that may hinder the enhancement of productivity as well as create a negative image to foreign countries.

Although the garment industry in Bangladesh is on her right track in competitive market, it has failed to ensure the proper rights of workers effectively. Unsound working condition, lack of safety in working place, low wage, excessive workload and, political instability are very crucial factors \& can reduce the overall productivity of RMG sector. Major Dhaka incidents like Tazreen fire in November 2012 and the Rana Plaza collapse in 2013 could make foreign buyers refuse to place order in Bangladesh which would destroy its valuable sector. Frequent strikes also create negative impact on the RMG sector. So, an institute management must have a reliable technique to enrich the productivity as well as put more focus on those criteria that can reduce the productivity. It helps promoting friendly relationship with buyers and deal with multiple conflicting criteria. Although various important platforms like the Bangladesh Accord on Fire and Building Safety, the Alliance for Bangladesh Worker Safety and National Plan of Action have been developed to reduce the problems.

In today's world, each department in an organization is concerned about how to improve productivity. It's a great challenge to thrive on productivity. An increment in Productivity level reduces product manufacturing cost. Hence a company can make more profit through productivity improvement. The aim of this study is to propose a model to find out the most crucial factors that must be overcome to sustain steady growth of RMG sector in Bangladesh. In the assessment procedure, AHP method has been applied to determine the weights of the criteria and to rank the candidates.

The rest of this study is arranged as follows: The second section presents the detailed literature review. Section 3 frameworks the developed methodology and provides a stepwise depiction of the anticipated AHP approach. In Section 4, in order to demonstrate the applicability of proposed model an illustrative example is presented. And finally, in section five, results of the application are analyzed and suggestions for the future studies are clarified. This section wraps up this study.

\section{LITERATURE REVIEW}

The rapid growing challenges like global competition, dependency on raw material, increased product variety, demanding customer and, globalization have a major influence on apparel industries. Apparel manufacturers need to produce the high quality products reducing the difficulties in operations for acquiring demand for higher value at lower price. In order to survive, they need to combat the constraints associated with the operations. In order to improve the 
productivity, it is vital to identify, quantify and remove the constraints. The industry can gain higher productivity and profitability with improved quality product by identifying and overcoming the problems that reduce the productivity, cost and improve internal throughout time.

Several researchers have worked in RMG sector and focused the prospects and challenges of it. A large number of recent studies have reported the increasing effects of hazardous working condition in the garment factory. Recently, a study of Bangladeshi garment workers, reported that hazardous working condition was significantly associated with musculoskeletal disorders, eye strain, neck, upper back and low back pain, less appetite, neural problem etc. (Paul-Majumder and Begum, 1997; Nahar et al., 2010; Drusilla et al., 2011; Ahmed \& Raihan, 2014). Among the common work-related problems, the musculoskeletal disorders are considered as a major one (Mehta, 2012).

Excessive workload is another problem in garment factory. Workers spend approximately two third of the day in factories. According to the study of several researchers, congested environment, excessive mental pressure to fulfill the target, awkward postures etc. affected their health (Jana, 2008; Alam, 2009; Ahmed \& Raihan, 2014). The female workers are supposed to work under mental pressure and sexually harassed by the supervisors in the garment factory at the night shipment. Women are preferred by the garment factory as they are easily manageable \& more vulnerable (Khan, 2001).

Dunn \& Mondal (2010) have showed that occupational safety and health policy are not recognised by the factory owners properly although they are alleged to comply. The core Occupational Safety and Health Convention (No. 155) are not sanctioned properly by Bangladesh. As Paul-Majumder (1998), female workers are supposed not to take babies in order to continue their jobs. Limited Emergency exit, narrow staircases, lack of fire protection, inappropriate building etc. have increased the rate of accidents. Rana Plaza collapse \& Tazreen fire in Decmber 2012 indicate the unsound working atmosphere of factory (Miller, 2012). Compensation should be given to workers in case of work-related accidents. But workers are not aware of their rights and the labour court system is vulnerable.

Although workers engage themselves for most of the day in factory without any time break but they do not get satisfactory money. With the little income by herculean task, they can't fulfill their basic needs and send their children to schools. A large number of recent studies have reported that inadequate wages are responsible for the labour unrest in the ready-made garment industry of Bangladesh (Absar, 2001; Islam and Ahmad, 2010; Ferdous, 2012; Islam and Ahmed, 2014).

There lies a strong relationship between political unrest \& level of productivity of the RMG industry. Political turbulence can reduce foreign currency by increasing buyer uncertainty and cost pressures. Due to political instability, buyers prefer to place orders in other countries. They don't totally cut their relationship with us but reduce the risk by dealing with others which ultimately have a negative impact on productivity (Berg et al., 2011). During strikes or locally known as hartals, workers do tend to arrive in proper time and it seems very vital if a line manager or supervisor is absent. It reduces the efficiency of an industry (Ahsan and Iqbal, 2014).

Uddin \& Tangem (2015) applied some statistical techniques to find out the factors responsible for the labor unrest in RMG factory in Bangladesh. The study indicated unjust payment behavior, absence of proper infrastructural facilities, and absence of proper recreation facilities, mental 
harassment etc. as vital factors causing labor unrest. This study has been conducted to prioritize the factors that can reduce the level of productivity of this multibillion dollar industry. A classical AHP method has been applied to rank the factors.

\section{PROPOSED MODEL}

Multi-Criteria Decision Making (MCDM) is the process of finding the best alternative from all of the feasibility alternatives while these alternatives are evaluated according to a number of criteria or attribute which are independent, incommensurate or conflicting. It is a process to refer the screening, prioritizing, ranking or selecting a set of criteria and based on the criteria prioritizing the alternatives (Hwang \& Yoon, 1981). Multi-Criteria Decision Making (MCDM) is also called Multi-Criteria Decision Analysis (MCDA) which is a subdivision of operation research that deals with designing mathematics and computational tools to support the subjective evaluation of a limited number of decision alternatives under a limited number of criteria by a single decision maker or by a group (Lootsma, 1999). Most commonly used MCDM methods is Analytical Hierarchy Process (AHP) which has been applied successfully in many practical decision making problems.

The main objective of this paper is to identify the criteria that are considered as the barriers for the enhancement of the productivity of a RMG industry as well as to rank them using AHP method. The evaluation process consists of three main steps as summarized below.

Step 1: Identify the evaluation criteria considered as the most important measures obstructing the productivity of a RMG industry.

Step 2: Construct the hierarchy of the evaluation criteria and calculate the weights of these criteria using AHP method.

Step 3: Rank the criteria.

The detailed descriptions of each step are illustrated in the following sections.

Determining the criteria weights by AHP

The analytic hierarchy process (AHP) developed by Thomas L. Saaty (1980) is a multiple criteria decision making tool which is used for organizing and analyzing complex problems with several attributes. AHP deals with the modeling of amorphous problems by creating hierarchical forms of different elements as principle goal, the goal affected by those criteria or the criteria that are affected by sub-criteria and not but the least the different substitutes available to the problem. Saaty 1-9 preference scale as shown in Table 1 has been applied to form a pair-wise comparison matrix from where the eigenvector and the maximum eigenvalue $\left(\lambda_{\max }\right)$ are derived and acquire the degree of relative importance of elements. Deriving the consistency index and consistency ratio denotes the final step.

The stepwise procedure of AHP is presented as follows:

Step 1: Construct the structural hierarchy.

Step 2: Construct the pair-wise comparison matrix. 
International Journal of Managing Value and Supply Chains (IJMVSC) Vol. 7, No. 3, September 2016

Assuming $\mathrm{n}$ attributes, the pairwise comparison of attribute $\mathrm{i}$ with attribute $\mathrm{j}$ yields a square matrix $A_{n \times n}$ where $\mathrm{a}_{\mathrm{ij}}$ denotes the comparative importance of attribute $\mathrm{i}$ with respect to attribute $\mathrm{j}$. In the matrix, $\mathrm{a}_{\mathrm{ij}}=1$ when $\mathrm{i}=\mathrm{j}$ and $\mathrm{a}_{\mathrm{ji}}=1 / \mathrm{a}_{\mathrm{ij}}$.

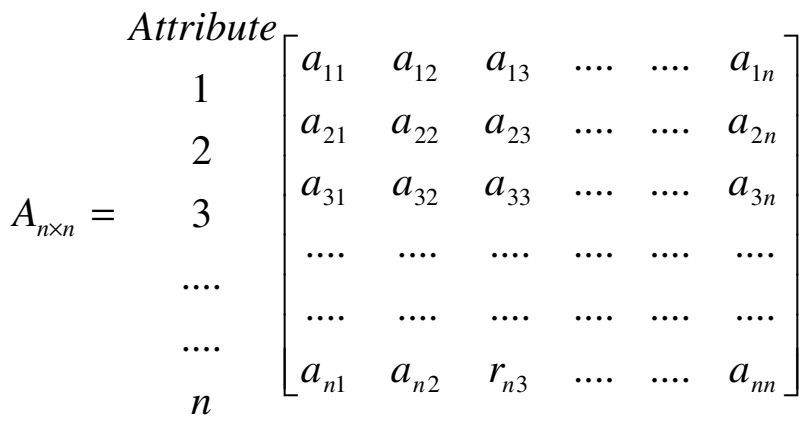

Step 3: Construct normalized decision matrix

$$
c_{i j}=a_{i j} \sum_{J=1}^{n} a_{i j} i=1,2,3, \ldots \ldots ., n ; j=1,2,3, \ldots \ldots ., n
$$

Step 4: Construct the weighted normalized decision matrix

$$
w_{i}=\sum_{J=1}^{n} c_{i j} / n \quad i=1,2,3, \ldots \ldots, n
$$

$W=\left[\begin{array}{c}w_{1} \\ w_{2} \\ \cdot \\ \cdot \\ w_{n}\end{array}\right]$

Step 5: Calculate Eigenvector \& Row matrix

$$
E=N^{\text {th }} \text { rootvalue } / \sum N^{\text {th }} \text { rootvalue }
$$

Rowmatrix $=\sum_{j=1}^{n} a_{i j} * e_{j 1}$

Step 6: Calculate the maximum Eigen value $\lambda_{\max }$.

$$
\lambda_{\max }=\text { Rowmatrix } / E
$$


Step 7: Calculate the consistency index \& consistency ratio.

$$
\begin{aligned}
& C I=\left(\lambda_{\max }-n\right) /(n-1) \\
& C R=C I / R I
\end{aligned}
$$

Where n \& RI (Table 4) denote order of matrix \& Randomly Generated Consistency Index respectively.

\section{APPLICATION OF THE MODEL WITH AN EXAMPLE}

The proposed model has been applied in RMG sector generating a plenty of foreign currency for identifying the precise factors that hinder productivity. There are a number of factors that are responsible for lowering productivity in garments. The management must have a reliable technique to identify the most prominent criteria as RMG is the leading sector of Bangladesh. A set of questionnaires were completed, key informant interviews were done together with Focus group Discussion. Consensus can play a vital role in any group decision making problems and shows the indication of group agreement or reliability. Therefore a group decision has been proposed to improve the pair-wise comparison in the evaluation process. To measure the weights of criteria by AHP method, pair wise comparison matrix, an input is developed. The hierarchical structure of the criteria adopted in this study is portrayed in Table 2.

To calculate the weights of the main criteria, three groups were formed consisting of 10 experts in the relevant field. Each group was asked through a questionnaire to specify the importance of the each evaluation criteria. Then, three pair-wise comparison matrixes were formed using Saaty's 19 scale considering the decision makers' subjective judgments. An aggregated pair-wise comparison matrix has been constructed by integrating three groups' grades which is shown in Table 3. The calculation of the weights is given as follows.

A normalized matrix, $C$ has been calculated by using Eq. (1):

$$
C=\left[\begin{array}{lllllllll}
0.22 & 0.12 & 0.22 & 0.30 & 0.14 & 0.19 & 0.25 & 0.15 & 0.20 \\
0.07 & 0.04 & 0.04 & 0.02 & 0.08 & 0.12 & 0.03 & 0.15 & 0.03 \\
0.22 & 0.20 & 0.22 & 0.30 & 0.19 & 0.12 & 0.25 & 0.20 & 0.20 \\
0.07 & 0.20 & 0.07 & 0.10 & 0.14 & 0.12 & 0.08 & 0.09 & 0.20 \\
0.04 & 0.01 & 0.03 & 0.02 & 0.03 & 0.01 & 0.02 & 0.01 & 0.04 \\
0.04 & 0.01 & 0.07 & 0.03 & 0.08 & 0.04 & 0.02 & 0.09 & 0.04 \\
0.07 & 0.12 & 0.07 & 0.10 & 0.14 & 0.19 & 0.08 & 0.15 & 0.07 \\
0.04 & 0.01 & 0.03 & 0.03 & 0.08 & 0.01 & 0.02 & 0.03 & 0.04 \\
0.22 & 0.29 & 0.22 & 0.10 & 0.14 & 0.19 & 0.25 & 0.15 & 0.20
\end{array}\right]
$$

Then the priority weights are calculated by using Eq. (2): 


$$
\begin{aligned}
& w_{1}=1.78 \times 1 / 9=0.20 \\
& w_{2}=0.58 \times 1 / 9=0.06 \\
& w_{3}=1.90 \times 1 / 9=0.21 \\
& w_{4}=1.07 \times 1 / 9=0.12 \\
& w_{9}=1.75 \times 1 / 9=0.19
\end{aligned}
$$

$$
\begin{aligned}
& w_{5}=0.21 \times 1 / 9=0.02 \\
& w_{6}=0.43 \times 1 / 9=0.05 \\
& w_{7}=0.99 \times 1 / 9=0.11 \\
& w_{8}=0.30 \times 1 / 9=0.03
\end{aligned}
$$

The normalized weight vector respect to main criteria is $W=(0.20,0.06,0.21,0.12,0.02,0.05,0.11,0.03,0.19)$. The Priority Matrix for the Criteria is portrayed in Fig. 1. The Fig. 1 shows that Unsound Working Condition, lack of safety policy \& low wage having priority of $0.21,0.20,0.19$ respectively are top three factors in the decision makers' subjective judgments which must be eliminated in order to enhance the foreign currency. They are followed by the others.

To calculate $\lambda_{\max }$, elements of the row matrix are estimated by using Eq. (5) and forms as (1.94, $0.59,2.07,1.17,0.22,0.43,1.07,0.30,1.94)$. Eq. (6) gives the nine estimates of $\lambda_{\max } \&$ the mean of these values (9.23) is the estimated $\lambda_{\max }$. Consistency Index (CI) \& Consistency Ratio (CR) are calculated through Eqs. (7) \& (8) respectively (for RI=1.45). As the value of CR (0.079) is less than 0.10 , it is accepted.

\section{RESULTS AND DISCUSSIONS}

Depending on the values of normalized weight vector of nine criteria, "unsound working condition" becomes the most dominating criteria having highest weight of 0.21 which is followed by the others. So, management must put more emphasis to combat against this factor along others.

\section{CONCLUSIONS AND FUTURE WORK}

Bangladesh has enormous opportunity to be the market leader for exporting the RMG in the world. Duty free excess to western markets, cheap labor, government's willingness, and, expansion of export processing zone (EPZ) pave the way for inclusive growth and ultimate profit of this sector. In spite of having extraordinary demand of garments' product, Bangladesh still faces some serious challenges in this sector. The working environment of most of the industries is not so good which also affect the workers working capability and directly on productivity. Besides, there is a discrimination of wage between men and women and unstructured payment system which create workers dissatisfaction. Sometimes this creates industrial unrest that shut down total production system and decreases the increasing trend of productivity. Lack of safety, excessive workload, skills of the workers should be received the greatest attention. If factors hindering productivity are identified and ranked properly, Bangladesh will ensure best and high quality products along with better labor condition. Due to this reason, the paper has undertaken an exemplar framework through analytic hierarchy process (AHP) algorithm which is an active instrument for classifying the key factors. This model plays a vital role to establish a concrete decision in group decision environment. The study can be extended in future by using some other 
MCDM methods such as ELECTRE; PROMETHEE; MOORA; TOPSIS; ORESTE etc. in a fuzzy environment. The study found out that "unsound working condition" among several challenges affects workers working capability and productivity most severely. The study recommends the management to find out factors hindering productivity and take corrective measures against them challenges that through proper identification and taking corrective measures against the challenges by the management. Through reducing the severity of the factors, Bangladesh has the opportunity to be the market leader in RMG exporting sector.

\section{ACKNOWLEDGEMENTS}

The authors wish to acknowledge the support and assistance provided by the EPIC group, LIZ Fashion Industry \& GMS knitting Industry located in Gazipur, Dhaka. The efforts of the managers of the industries, workers and supervisors of those RMG industries who collaborated in this study are also appreciated.

\section{REFERENCE}

1. Absar, S.S.(2001).Problems Surrounding Wages; The Readymade Garments Sectors in Bangladesh. Journal of LMD Labor and Management in Development, 2,7.

2. Ahmed, S., and Raihan, M.Z. (2014).Health Status of the Female Workers in the Garment Sector of Bangladesh.Journal of The Faculty of Economics and Administrative Sciences, 4(1), 43-58.

3. Ahsan, R.N., and Iqbal, K. (2014).Political strikes and its impact on trade: Evidence from Bangladeshi transaction-level export data. International Growth Center.

4. Berg, Achim, Herdich, S., and Kempf, S. (2011).Bangladesh's ready-made garments landscape: The challenge of growth. McKinsey \& Company, Inc.

5. Drusilla, K.B., Deardorff, A.V., and Stern, R.M. (2011).Labor Standards and Human Rights; Implications for International Trade and Investment. International Policy Center, 119.

6. Dunn, K., and Mondal, A.H. (2010).Report on the Review of the Decent Work Country Programme: Bangladesh 2006-2009. ILO Regional Office for Asia and the Pacific. Bangkok: ILO.

7. Farhana, K., Syduzzaman, M., and Munir, M.S. (2015). Present Status of Workers in Readymade Garments Industries in Bangladesh. European Scientific Journal, 11(7).

8. http://www.garmentsmerchandising.com/

9. Hwang, C. L., and Yoon, K. (1981).Multiple attributes decision making methods and applications. Berlin: Springer.

10. Islam, M.S., and Ahmed, S. (2010).Contemplating Sustainable Solutions to Garments Sector Unrest.The Daily Star, 10 July.

11. Islam, N., and Ahmed, S. (2014).Socioeconomic Factors and Labor Unrest in Ready Made Garment Industry of Bangladesh. Journal of Education Research and Behavioral Sciences, $3(2), 65-74$.

12. Jana, P. (2008).Ergonomics in Apparel Manufacturing-I, Importance and Impact of Ergonomics.Stitch World, 6, 42-47.

13. Khan, S.I. (2001).Trade Unions, Gender Issues and the Ready Garment Industry of Bangladesh. Report of the United Nations Research Institute for Social Development.

14. Lootsma, F. A. (1999).Multi-criteria decision analysis via ratio and difference judgment. Kluwer Academic Publishers.

15. Mehta, R. (2012).Major Health Risk Factors prevailing in Garment Manufacturing Units of Jaipur.International Journal of Ergonomics, 2(2), 102.

16. Miller, D. (2012).Last Nightshift in Savar: The Story of the Spectrum Sweater Factory Collapse. Newcastle: McNidder and Grace. 
17. Nahar, N., Ali, R.N., and Begum, F. (2010).Occupational Health Hazards in Garment Sector. International Journal of Bio Res, 1(2), 1-6.

18. Paul-Majumder, P., and Begum, S. (1997).Upward Occupational Mobility among Female Workers in the Garment Industry of Bangladesh. Bangladesh Institute of Development Studies (BIDS), Dhaka, Bangladesh, 153.

19. Saaty,T.L.(1980). The Analytic Hierarchy Process.McGraw-Hill, New York.

20. Uddin, M.I., and Tangem, S. (2015). A Study on the Relationship between Working Environment and Labor Unrest in Ready-Made Garment (RMG) Industry of Bangladesh. International Journal of Management Sciences and Business Research, 4(9).

\section{List of Tables}

Table 1 Saaty's pair-wise comparison scale

\begin{tabular}{cc}
\hline Scale & Compare factor of $\mathrm{I} \& \mathrm{j}$ \\
\hline 1 & Equally Important \\
3 & Weakly Important \\
5 & Strongly Important \\
7 & Very strongly Important \\
9 & Extremely Important \\
$2,4,6,8$ & Intermediate value between adjacent scales \\
\hline
\end{tabular}

Table 2 Hierarchical Representation of Criteria

\begin{tabular}{cc}
\hline Main Criteria & Symbol \\
\hline Lack of safety policy & $\mathrm{C}_{1}$ \\
political unrest & $\mathrm{C}_{2}$ \\
Unsound working environment & $\mathrm{C}_{3}$ \\
lack of labor regulations & $\mathrm{C}_{4}$ \\
Excessive workload & $\mathrm{C}_{5}$ \\
Unskilled workers & $\mathrm{C}_{6}$ \\
Lack of managerial knowledge & $\mathrm{C}_{7}$ \\
Utility crisis & $\mathrm{C}_{8}$ \\
Low wage & $\mathrm{C}_{9}$ \\
\hline
\end{tabular}

Table 3 Aggregated pair-wise comparison matrix

\begin{tabular}{cccccccccc}
\hline & $\mathrm{C}_{1}$ & $\mathrm{C}_{2}$ & $\mathrm{C}_{3}$ & $\mathrm{C}_{4}$ & $\mathrm{C}_{5}$ & $\mathrm{C}_{6}$ & $\mathrm{C}_{7}$ & $\mathrm{C}_{8}$ & $\mathrm{C}_{9}$ \\
\hline $\mathrm{C}_{1}$ & 1.00 & 3.00 & 1.00 & 3.00 & 5.00 & 5.00 & 3.00 & 5.00 & 1.00 \\
$\mathrm{C}_{2}$ & 0.33 & 1.00 & 0.20 & 0.20 & 3.00 & 3.00 & 0.33 & 5.00 & 0.14 \\
$\mathrm{C}_{3}$ & 1.00 & 5.00 & 1.00 & 3.00 & 7.00 & 3.00 & 3.00 & 7.00 & 1.00 \\
$\mathrm{C}_{4}$ & 0.33 & 5.00 & 0.33 & 1.00 & 5.00 & 3.00 & 1.00 & 3.00 & 1.00 \\
$\mathrm{C}_{5}$ & 0.20 & 0.33 & 0.14 & 0.20 & 1.00 & 0.33 & 0.20 & 0.33 & 0.20 \\
$\mathrm{C}_{6}$ & 0.20 & 0.33 & 0.33 & 0.33 & 3.00 & 1.00 & 0.20 & 3.00 & 0.20 \\
\hline
\end{tabular}


International Journal of Managing Value and Supply Chains (IJMVSC) Vol. 7, No. 3, September 2016

\begin{tabular}{llllllllll}
\hline $\mathrm{C}_{7}$ & 0.33 & 3.03 & 0.33 & 1.00 & 5.00 & 5.00 & 1.00 & 5.00 & 0.33 \\
$\mathrm{C}_{8}$ & 0.20 & 0.20 & 0.14 & 0.33 & 3.00 & 0.33 & 0.20 & 1.00 & 0.20 \\
$\mathrm{C}_{9}$ & 1.00 & 7.14 & 1.00 & 1.00 & 5.00 & 5.00 & 3.03 & 5.00 & 1.00 \\
\hline
\end{tabular}

Table 4 Average Random Index

\begin{tabular}{|l|l|l|l|l|l|l|l|l|l|l|}
\hline $\mathrm{N}$ & 1 & 2 & 3 & 4 & 5 & 6 & 7 & 8 & 9 & 10 \\
\hline $\mathrm{RI}$ & 0 & 0 & 0.58 & 0.90 & 1.12 & 1.24 & 1.32 & 1.41 & 1.45 & 1.49 \\
\hline
\end{tabular}

\section{List of Figure}

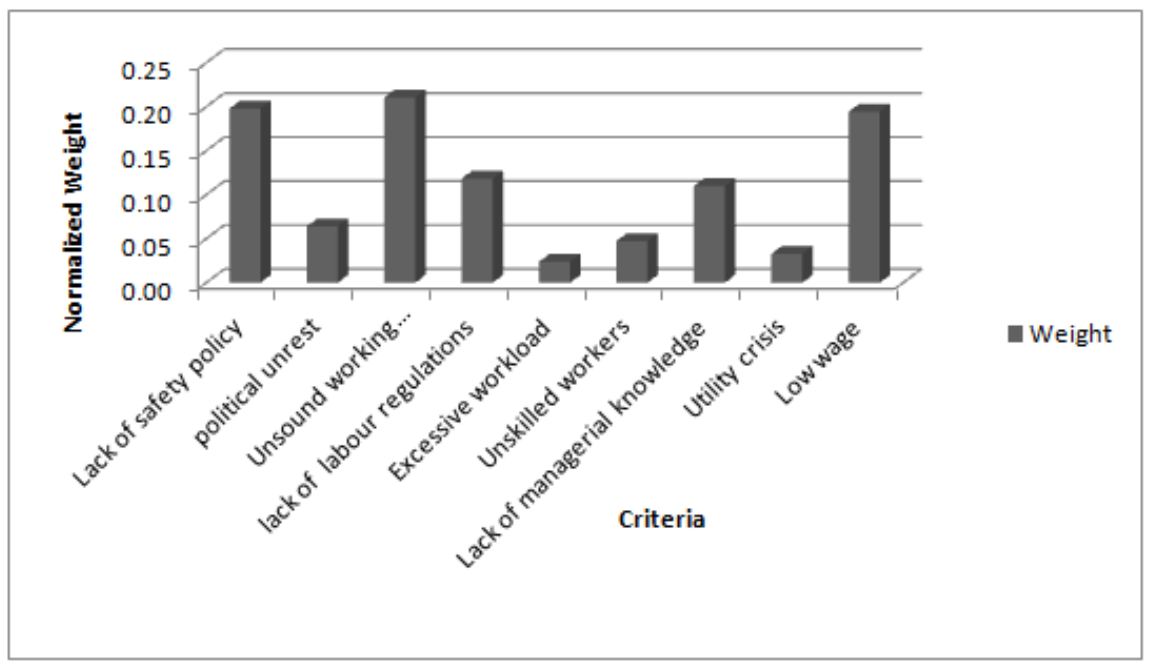

Fig1: Normalized weights of criteria obtained from AHP 